\title{
Clinical Study \\ Characteristics of Atopic Bronchial Asthma in Seniors over 80 Years of Age
}

\author{
Andrzej Bożek, ${ }^{1}$ Marek Filipowski, ${ }^{2}$ Andreas Fischer, ${ }^{3}$ and Jerzy Jarzab ${ }^{1}$ \\ ${ }^{1}$ Clinical Department of Internal Medicine, Dermatology and Allergology, Medical University of Silesia, M. Sklodowskiej-Curie 10, \\ 41-800 Zabrze, Poland \\ ${ }^{2}$ Clinical Department of Chest Surgery, Medical University of Silesia, 41-880 Zabrze, Poland \\ ${ }^{3}$ Genetic Laboratory MTD, 80-331 Munchen, Germany \\ Correspondence should be addressed to Andrzej Bożek; andrzejbozek@o2.pl
}

Received 23 April 2013; Revised 1 July 2013; Accepted 1 July 2013

Academic Editor: Fulvio Braido

Copyright (C) 2013 Andrzej Bożek et al. This is an open access article distributed under the Creative Commons Attribution License, which permits unrestricted use, distribution, and reproduction in any medium, provided the original work is properly cited.

Background. Asthma in the elderly is an important public health problem. The aim of this study was to assess the prevalence and characteristics of asthma in seniors. Materials and Methods. The study involved 105 people of at least 80 years of age (mean age of $84.1 \pm 3.9$ years) selected from a group of 1860 individuals. Spirometry, the methacholine test, allergy diagnosis, a measurement of exhaled nitric oxide, and administration of the asthma quality of life questionnaire (AQLQ) were performed. Results. The average morbidity of asthma in the study population of elderly people (at least 80 years of age) was $5.6 \%$ (105 people) of the confidence interval (95\% CI: 5.1-6.0). In the study group, $34 \%$ of the elderly asthmatics had uncontrolled asthma, $47 \%$ had partly controlled asthma, and only $24 \%$ had fully controlled asthma. Allergy to house dust mites was predominant. The average total score on the AQLQ was $4.12 \pm 0.72$ (arithmetic mean \pm standard deviation) for the seniors, which was significantly lower than the score for the young. Conclusion. The pathogenesis, natural history, and value of the basic diagnostic methods of asthma in the elderly are similar to those observed in younger age groups.

\section{Background}

Bronchial asthma is an increasing problem in all age groups. However, there is still not enough information about the natural course and clinical features of asthma in seniors. Additionally, a clear diagnosis of asthma in patients over 80 years of age is difficult $[1,2]$. Similarities between COPD and asthma, overlap syndrome and the presence of other diseases make it difficult to diagnose asthma in elderly patients. Many older patients are still underdiagnosed [1-4]. This phenomenon results in the undertreatment of asthma and leads to a deterioration in quality of life [4]. This group of patients is frequently incorrectly diagnosed with COPD, and seniors are unwilling to undergo diagnostic tests for allergy $[3,5]$.

The aim of the study was to assess the differences between the clinical features of asthma in patients over 80 years old and youth. This study could successfully draw the necessary attention to the special needs of these patients.

\section{Materials and Methods}

The study group enrolled 105 patients who were at least 80 years old and had a preliminary diagnosis of asthma. The recruitment of respondents was conducted in eight centers representative of the Polish population. Stratification sampling was performed from 1860 patients in the key age group of over 80 years of age. The control group consisted of young patients diagnosed with asthma and selected from GP clinics in the same areas of residence as the group of elderly patients. Stratification sampling was also performed, with a key age group of 18-30 years of age. Asthma was diagnosed on the basis of the ECRHS II questionnaire [6], a physical examination, and spirometry with a positive result for the reversibility test (Lungtest 1000, MES, Krakow, Poland) or with a positive result for the methacholine test. For a positive test result, an increase in the forced expiratory volume in one second (FEV1) of $\geq 12 \%$ or an increase of $200 \mathrm{~mL}$ was necessary, in accordance with the criteria of the ATS and ERS [7]. 
Before testing, the patients did not use a short-acting beta2 agonist for 8 hours, ipratropium and theophylline derivatives for 24 hours, a long-acting beta 2 agonist for 48 hours, or tiotropium for 72 hours. Current smokers refrained from smoking for 1 hour before testing. Testing was delayed for 4 weeks in the case of respiratory tract infections. The methacholine test was performed based on the standards of the Polish Society of Allergology [8]. A positive result for the test corresponded to a decline in the FEV1 of $20 \%$ and a PC20 of $<8 \mathrm{mg} / \mathrm{mL}$. The subjects completed the asthma control test (ACT) [9]. The asthma severity and control of the disease were determined on the basis of an interview and spirometry test and assessed according criteria of Global Initiative for Asthma (GINA) [10]. Patients with negative reversibility test and with clinical manifestations of COPD or asthma/COPD overlap syndrome were excluded from the study. All subjects signed a consent form, agreeing to participate in the study.

\section{Allergy Testing}

3.1. Concentration of IgE. Measurement of the concentration of total $\operatorname{IgE}$ and allergen-specific $\operatorname{IgE}(\operatorname{sg} \mathrm{E})$ was performed using the Pharmacia CAP System FEIA (Pharmacia AB, Uppsala, Sweden), and the values are shown in $\mathrm{kU} / \mathrm{l}$ [11]. Research was performed for the following specific IgE allergens: Dermatophagoides pteronyssinus, Dermatophagoides farinae, Aspergillus fumigatus, Alternaria tennis, Cladosporium herbarum, dog dander, cat dander, grass mix, birch, alder, hazel, and mugwort. IgE values above $0.35 \mathrm{kU} / 1$ were considered to be a positive result [11].

3.2. Skin Prick Tests (SPTs). In the study, SPTs were obtained from Allergopharma (Reinbeck, Germany), corresponding to a set of allergen-specific IgEs. The tests were performed according to the guidelines [12].

3.3. Exhaled Nitric Oxide. The level of fractional exhaled nitric oxide (FENO) was assessed in the senior group of patients and the young asthmatic control group. The determination of FENO was performed using a manual analyzer, the MINO Airway Inflammation Niox Monitor (Aerocrine $A B$, Solna, Sweden), measuring the exhaled fraction of nitric oxide by an electrochemical method [13]. The patients performed three repeated attempts to exhale into a mouthpiece device while maintaining a constant positive pressure between 12 and $18 \mathrm{~cm}$ water head to maintain a flow of air of $50 \pm 5 \mathrm{~mL} / \mathrm{s}$, in accordance with the recommendations of the American Thoracic Society [14]. The patients did not smoke cigarettes for 20 minutes before the test, did not eat foods rich in nitrogen for one day before the test, and did not take inhaled drugs (beta2 agonists and inhaled steroids) for 6 hours before the test. The study excluded patients with symptoms of respiratory infection. FaENO values were reported in parts per billion ( $\mathrm{ppb}$ ). The value ranged from 5 to $300 \mathrm{ppb}$. For this analysis, the mean of three reproducible results were used.

A patient quality-of-life assessment was performed using the asthma quality of life questionnaire (AQLQ) developed by
Juniper, whose application was approved. The questionnaire included questions about the group: the environmental exposure of the patients, the reduction in physical activity by the disease, the patient's emotional evaluation in the context of the disease, and the symptoms of the disease itself. For each of the 32 questions, the patient responded on a scale of 1-9 points, with the lowest to the highest value representing the worst to the best assessment. Details of the questionnaire can be found in the literature [15].

3.4. Statistical Analysis. For comparison, data meeting the criterion of a normal distribution, such as the age of the participants, the duration of the disease, and the results of the spirometry tests, were analyzed using a Student's $t$-test for independent samples. To assess the correlation of the results of the skin tests and IgE measurements, Spearman's test was used. In addition, the logarithms of the IgE values met the criterion for a normal distribution, so Pearson's correlation test was used. Odds ratios were calculated to assess the likelihood of asthma in the presence of a particular trait in the subjects. Multiple linear regression analysis was used for the dependent variable, which was the duration of asthma, and for independent variables, such as smoking, the IgE value, asthma control, the ACT score, the severity of asthma, and the presence of allergic rhinitis. The statistical analyses used a Bonferroni correction. A $P$ value of $<0.05$ was considered significant.

The study was approved by the Bioethical Committee of the University Medical School of Silesia in Katowice, Poland.

\section{Results}

Based on data from 1860 screened individuals, the prevalence of asthma associated with age and sex in the study population of elderly people (at least 80 years of age) was 5.6\% (105 people) of the confidence interval (95\% CI: 5.1-6.0). There were 63 women and 42 men with a mean age of $84.1 \pm 3.9$ years (range of 80 to 97 years). The control group included 102 young patients with a mean age of $22.1 \pm 5.2$ years (range of 18 to 32 years), including 45 women and 67 men.

The demographic data for the patients and the degree of the control of asthma are shown in Table 1.

The mean spirometric values were as follows: mean FEV1 in elderly asthmatics: $1.21 \pm 0.45 \mathrm{~L}$ (mean $68.4 \%$ of the predicted value); mean FVC in elderly asthmatics: $1.73 \pm 0.43 \mathrm{~L}(77.4 \%$ of predicted value); mean FEV1 in young asthmatics: $1.87 \pm 0.49 \mathrm{~L}(73.1 \%$ of predicted value); and mean FVC in young asthmatics: $2.31 \pm 0.69 \mathrm{~L}$ (83.2\% of predicted value). There was a significant difference between the elderly and youth in absolute value $(P<0.05)$. However, there was no statistical difference between percentage of normal range according to age which was obtained by elderly and young. An allergy to the house dust mite D. pteronyssinus and/or D. farinae (positive skin tests and corresponding IgE) was predominant in approximately $47 \%$ and $45 \%$ of the young and old patients, respectively. This followed by a grass pollens $(27 \%$ in elderly versus $24 \%$ in young), tree pollens (29\% versus $28 \%$ ), 
TABLE 1: Clinical characteristic of asthma: comparison between seniors and youth.

\begin{tabular}{lccc}
\hline Characteristics & $\begin{array}{c}\text { Seniors } \\
n=105\end{array}$ & $\begin{array}{c}\text { Youth } \\
n=102\end{array}$ & $P$ \\
\hline Mean age & $84.1 \pm 3.9$ & $22.1 \pm 5.2$ & $<0.05$ \\
Women (\%) & $63(60)$ & $45(44)$ & $<0.05$ \\
Smokers (\%) & $7(6.7)$ & $9(8.2)$ & NS \\
Former smokers (\%) & $13(12,4)$ & $6(5.9)$ & NS \\
Duration of asthma & $29.2 \pm 5.1$ & $2.4 \pm 1.6$ & $<0.05$ \\
Late onset of asthma & $68(17.6)$ & - & - \\
(after 65 years; \%) & $13.9 \pm 4.8$ & $15.7 \pm 3.7$ & NS \\
Mean result of ACT & $32(8.4)$ & $23(5.7)$ & NS \\
Severe asthma (\%) & $38(36)$ & $29(28.8)$ & NS \\
Moderate asthma (\%) & $43(40.6)$ & $43(41.8)$ & NS \\
Mild asthma (\%) & $24(22.8)$ & $48(46.2)$ & $<0.05$ \\
Fully controlled asthma & $47(44.8)$ & $49(48)$ & NS \\
Partly controlled asthma & $43(32.2)$ & $6(5.8)$ & $<0.05$ \\
Uncontrolled asthma & $34.7)$ & $63(61.7)$ & NS \\
Allergic rhinitis & $59(56.3)$ & &
\end{tabular}

NS: not significant.

cockroach (21\% versus $19 \%)$, molds (15\% versus $9 \%)$, and animal dander (10\% versus $9 \%)$. The results of the tests, including for specific IgE, were comparable between the two groups, except for a significant predominance of allergy to molds in the elderly $(P<0.05)$.

The analysis of the impact of various factors on the presence of asthma in studied subjects were performed and showed in Table 2.

The total serum IgE was $189.4 \pm 38.7 \mathrm{kU} / \mathrm{L}$ in elderly and $201.7 \pm 78.9 \mathrm{kU} / \mathrm{L}$ in control group. There was no statistical difference.

In all patients, the initial diagnosis of seniors was performed with an asthma reversibility test, which was positive in $86(78 \%)$ patients (increase in the FEV1 of $\geq 12 \%$ or an increase of $200 \mathrm{~mL}$ ). In total, $11(10.5 \%)$ patients had negative result of reversibility test. In $8(7 \%)$ patients, the test could not be performed because of a lack of cooperation. Patients in the last two subgroups (11 plus 8 people) underwent assessment with a test for methacholine bronchial hyperreactivity, which indicated that $14(13.3 \%)$ patients met the criterion for the diagnosis of asthma (FEV1 decline of $20 \%$ ). Due to a low FEV1 value ( $<70 \%$ of normal and less than 11$), 17$ patients withdrew from the study. Finally, 5 (4.8\%) patients were classified into groups with COPD or asthma/COPD overlap syndrome (characteristic clinical manifestation, changes in $\mathrm{X}$-ray, negative reversibility test). They were excluded from the study. The evaluation of the measurement of nitric oxide is shown in Table 3.

The average total score on the AQLQ was $4.12 \pm 0.72$ (arithmetic mean \pm standard deviation) for seniors, which was significantly lower than the score for the youth: $5.12 \pm$ 0.48 (Student's $t$-test, $P<0.05$ ). A similar trend was observed for each of the analyzed domains: environmental exposure: $4.13 \pm 0.53$ in seniors versus $5.16 \pm 0.33$ in young $(P<0.05)$;
TABLE 2: The odds ratio for asthma in elderly patients with analysis various factors.

\begin{tabular}{lc}
\hline Factors & $\begin{array}{c}\text { Odds ratio } \\
(95 \% \mathrm{CI})\end{array}$ \\
\hline History of atopy at a younger age & $1.54(1.36-1.78)$ \\
A positive result for at least one skin test & $2.01(1.86-2.11)$ \\
A positive allergen-specific IgE test & $2.08(1.98-2.56)$ \\
Smokers & $1.88(1.75-1.91)$ \\
Presence of asthma in at least one family & $1.47(1.26-1.62)$ \\
member & $1.49(1.23-1.98)$ \\
Men &
\end{tabular}

emotional function: $4.32 \pm 0.61$ versus $4.90 \pm 0.34(P<0.05)$; and activity: $4.01 \pm 0.55$ versus $5.4 \pm 0.63(P<0.05)$. The quality of life was significantly correlated with better asthma control according to the ACT (Spearman's rank correlation test, $R=0.87, P<0.05)$. AQLQ scores did not correlate with spirometric values (FEV1).

\section{Discussion}

The obtained results showed lack of significant differences between clinical features of asthma in seniors and young. The severity of the disease, the result of ACT, and the degree of asthma control were similar to young patients. This phenomenon is interesting and contradicts the observations between asthmatic patients aged 50-70 years compared with the young as it was confirmed in previous studies $[16,17]$ where more severe and frequent uncontrolled asthma in older patients was noticed. This can be explained by the overall good health condition of the respondents, which allowed them to survive more than 80 years of age. Lifestyle and genetic factors may play a fundamental role here. The analyzed group of patients, with asthma and over 80 years of age, is only one of such study. The other studies did not analyse homogenous populations, and majority of patients were in age range 50-80 [16-20]. The prevalence of asthma observed in the study did not differ significantly from the data available in the literature [18-20]. Among the analyzed patients with asthma, the percentage of those who were women was $56 \%$. This finding is a consequence of the predominance of women in the general population of seniors. The distribution of asthma presented in the literature, characterized by a long duration of the disease or a late-onset form, was also reflected in this study [17]. Nearly $18 \%$ of patients experienced asthma symptoms at 65 years of age. Despite reports $[16,21,22]$ of their differences in relation to long-duration asthma, such as milder, more asymptomatic days; less hospitalization; and improved spirometric parameters, these features were not observed in the current study. Confirmed great influence atopy on the development of asthma is well documented also in other studies, although in a slightly younger age groups [22-24]. This is another evidence of the nature of asthma, regardless of age. Allergic profile with domination of house dust mite allergy was comparable with results of other authors $[23,24]$. On the other hand, many studies 
TABLE 3: Comparison of exhaled nitric oxide in young and old patients with asthma.

\begin{tabular}{lccr}
\hline Subjects & $\begin{array}{c}\text { FENO (ppb), seniors } \\
(\text { mean } \pm \text { SD) }\end{array}$ & $\begin{array}{c}\text { FENO (ppb), youth } \\
(\text { mean } \pm \text { SD) }\end{array}$ & $P^{\wedge}$ \\
\hline All with asthma & $41.2 \pm 15.04$ & $32.74 \pm 12.62$ & $<0.05$ \\
Smokers with asthma & $46.09 \pm 25.33$ & $39.09 \pm 15.66$ & $<0.05$ \\
Nonsmokers with asthma & $38.03 \pm 13.2$ & $27.8 \pm 11.09$ & $<0.05$ \\
\hline
\end{tabular}

Student's $t$-test for unrelated samples with Bonferroni correction.

have shown a low reactivity of skin to testing and decrease in IgE-dependent activity in the elderly. However, it did not negate the importance of diagnostic IgE mediated reaction in this group $[16,17]$. The comparable value of total $\operatorname{IgE}$ in elderly and young confirmed the consistent prevalence of allergy, regardless of age. It was opposite to other observations $[16,17]$. Additionally, the results showed that smoking is not such a problem as it is commonly thought in patients with asthma. We also did not observe any coincidences between smoking and course of asthma and value of IgE. It was faced with conflicting evidences [19-21]. This may be due to very old age.

The performed pulmonary function studies highlighted the value of spirometry in the diagnosis and monitoring of asthma in older patients. There was no significant difference in reversibility tests and obtained percentage of normal ranges of of FEV1 and FVC. However, there are differences between absolute values of FEvl and FVC as it was in previous observations $[17,18]$. The lower absolute values observed in older asthmatics than in young asthmatics are proof of the aging process of the respiratory system, with an additional loss of capacity due to prolonged illness. This finding was indicated by previous reports [16-18]. Few studies have raised the issue of performing spirometry in the elderly. Chotirmall indicated the importance of this research to the diagnosis and assessment of asthma in the elderly but also emphasized possible limitations, such as poor cooperation due to cognitive impairment, poor psychomotor coordination, problems with the foundation of the mouthpiece, impaired perception, a poor response to beta 2 agonists, and a lack of capacity to perform forced expiration [17]. Pezzoli et al. emphasized the effectiveness of the implementation of spirometry in the elderly [25]. The use of nitric oxide measurements to assess bronchial asthma in the elderly, based on the results, appears to be useful. The higher obtained FENO in the elderly patients may be an evidence of much more advanced inflammation in the airways. This phenomenon may be a consequence of longterm asthma, which is often under-treated, and of systemic subinflammation in the elderly. There was no comparable data in this age range in other studies.

The worse quality of life in seniors with confirmed asthma than in the young may be an evidence for the poorer diagnosis and treatment of and interest in this group of patients. It is emphasizes earlier $[17,19]$.

\section{Conclusion}

Asthma in the elderly is an important public health problem. This condition's pathogenesis and natural history and the value of basic diagnostic methods are similar to those observed in younger age groups. There is a need to pay more attention to the disease in patients over 80 years old, which would prevent the underdiagnosis and undertreatment of asthma.

\section{References}

[1] S. S. Braman, "Asthma in the elderly," Clinics in Geriatric Medicine, vol. 19, no. 1, pp. 57-75, 2003.

[2] D. L. Urso, "Asthma in the elderly," Current Gerontology and Geriatrics Research, vol. 2009, Article ID 858415, 5 pages, 2009.

[3] E. Stupka and R. deShazo, "Asthma in seniors: part 1. Evidence for underdiagnosis, undertreatment, and increasing morbidity and mortality," American Journal of Medicine, vol. 122, no. 1, pp. 6-11, 2009.

[4] G. B. Marks, L. M. Poulos, C. R. Jenkins, and P. G. Gibson, "Asthma in older adults: a holistic, person-centred and problem-oriented approach," Medical Journal of Australia, vol. 191, no. 4, pp. 197-199, 2009.

[5] M. J. King, T. Tamulis, and R. F. Lockey, "Prick puncture skin tests and serum specific IgE as predictors of nasal challenge response to Dermatophagoides pteronyssinus in older adults," Annals of Allergy, Asthma and Immunology, vol. 101, no. 1, pp. 12-17, 2008.

[6] C. Janson, J. Anto, P. Burney et al., "The European community respiratory health survey: what are the main results so far?" European Respiratory Journal, vol. 18, no. 3, pp. 598-611, 2001.

[7] V. Brusasco, R. Crapo, G. Viegi, American Thoracic Society, and European Respiratory Society, "Coming together: the ATS/ERS consensus on clinical pulmonary function testing," European Respiratory Journal, vol. 26, no. 1, pp. 153-161, 2005.

[8] P. Górski and M. Szmit, "Testy prowokacyjne w alergii wziewnej. Komisja ds. Standardów. Zarządu Głównego Polskiego Towarzystwa Alergologicznego, red," Standardy w Alergologii, vol. 1, pp. 37-43, 2003.

[9] M. Schatz, C. A. Sorkness, J. T. Li et al., "Asthma control test: reliability, validity, and responsiveness in patients not previously followed by asthma specialists," Journal of Allergy and Clinical Immunology, vol. 117, no. 3, pp. 549-556, 2006.

[10] Global Initiative for Asthma Guidelines: http://www.gina.com/, 2012.

[11] Pharmacia CAP System FEIA, Manual Brochure, Ver 1. 0, Pharmacia CAP System FEIA, Uppsala, Sweden, 2002.

[12] J. Kruszewski, "Komisja ds. Standardów Zarządu Głównego Polskiego Towarzystwa Alergologicznego pod red. J. Kruszewskiego:", Standardy w Alergologii, vol. 1, pp. 9-29, 2003.

[13] P. E. Silkoff, M. Carlson, T. Bourke, R. Katial, E. Ögren, and S. J. Szefler, "The Aerocrine exhaled nitric oxide monitoring system NIOX is cleared by the US Food and Drug Administration for 
monitoring therapy in asthma," Journal of Allergy and Clinical Immunology, vol. 114, no. 5, pp. 1241-1256, 2004.

[14] American Thoracic Society and European Respiratory Society, "ATS/ERS recommendation for stan- dardized procedures for the online and offline measurements of exhaled lower respiratory nitric oxide and nasal nitric oxide," American Journal of Respiratory and Critical Care Medicine, vol. 171, no. 8, pp. 912930, 2005.

[15] E. F. Juniper, "Quality of life in adults and children with asthma and rhinitis," Allergy, vol. 52, no. 10, pp. 971-977, 1997.

[16] M. J. Connolly, "Asthma and chronic obstructive pulmonary disease," in Brocklehurst's Textbook of Geriatrics Medicine and Gerontology, R. C. Tallis and H. M. Fillit, Eds., pp. 489-493, Churchill Livingstone, New York, NY, USA, 2003.

[17] S. H. Chotirmall, M. Watts, P. Branagan, C. F. Donegan, A. Moore, and N. G. McElvaney, "Diagnosis and management of asthma in older adults: progress in geriatrics," Journal of the American Geriatrics Society, vol. 57, no. 5, pp. 901-909, 2009.

[18] C. A. E. Dyer, S. L. Hill, R. A. Stockley, and A. J. Sinclair, "Quality of life in elderly subjects with a diagnostic label of asthma from general practice registers," European Respiratory Journal, vol. 14, no. 1, pp. 39-45, 1999.

[19] R. G. Slavin, T. Haselkorn, J. H. Lee, B. Zheng, Y. Deniz, and S. E. Wenzel, "Asthma in older adults: observations from the epidemiology and natural history of asthma: outcomes and treatment regimens (TENOR) study," Annals of Allergy, Asthma and Immunology, vol. 96, no. 3, pp. 383-384, 2006.

[20] M. Wolkewitz, D. Rothenbacher, M. Löw et al., "Lifetime prevalence of self-reported atopic diseases in a populationbased sample of elderly subjects: results of the ESTHER study," British Journal of Dermatology, vol. 156, no. 4, pp. 693-697, 2007.

[21] N. E. Cousens, D. P. Goeman, J. A. Douglass, and C. R. Jenkins, "The needs of older people with asthma," Australian Family physician, vol. 36, no. 9, pp. 729-731, 2007.

[22] S. A. Quadrelli and A. J. Roncoroni, "Is asthma in the elderly really different?” Respiration, vol. 65, no. 5, pp. 347-353, 1998.

[23] S. Yokota, F. Mitsunobu, T. Mifune et al., "Age-related changes of IgE-mediated allergic reaction in patients with late onset asthma. Relationship between IgE-mediated allergy and age at onset," Japanese Journal of Geriatrics, vol. 35, no. 5, pp. 367-373, 1998.

[24] K. Huss, P. L. Naumann, P. J. Mason et al., "Asthma severity, atopic status, allergen exposure, and quality of life in elderly persons," Annals of Allergy, Asthma and Immunology, vol. 86, no. 5, pp. 492-493, 2001.

[25] L. Pezzoli, G. Giardini, S. Consonni et al., "Quality of spirometric performance in older people," Age and Ageing, vol. 32, no. 1, pp. 43-46, 2003. 


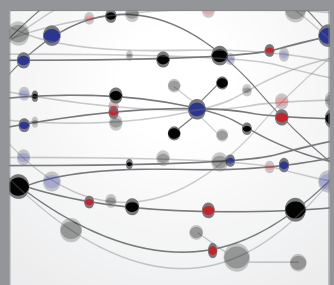

The Scientific World Journal
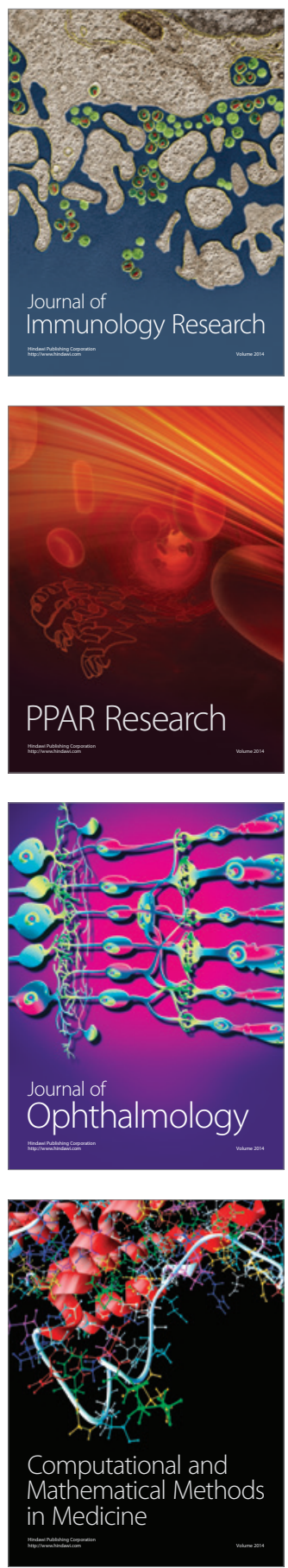

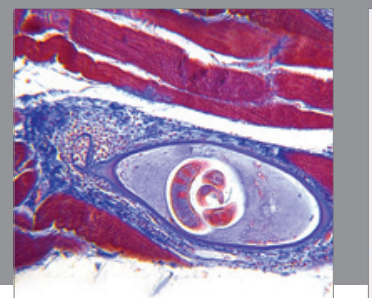

Gastroenterology

Research and Practice
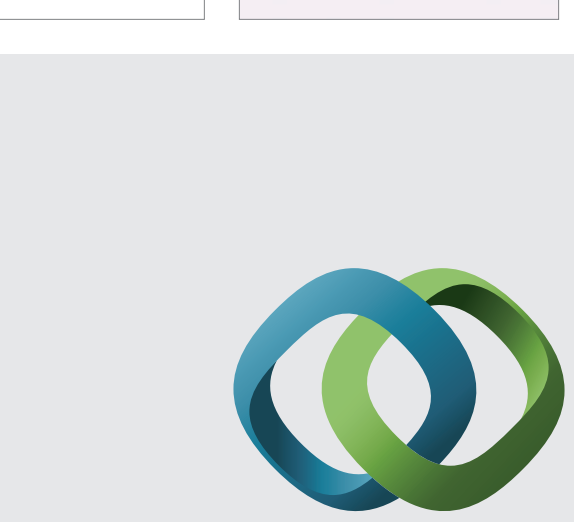

\section{Hindawi}

Submit your manuscripts at

http://www.hindawi.com
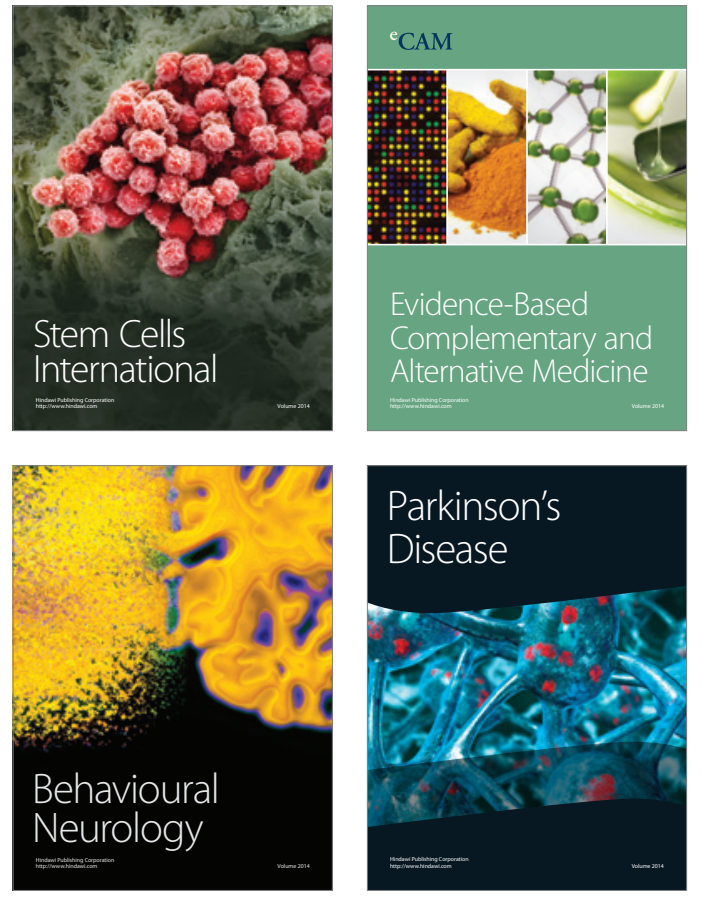
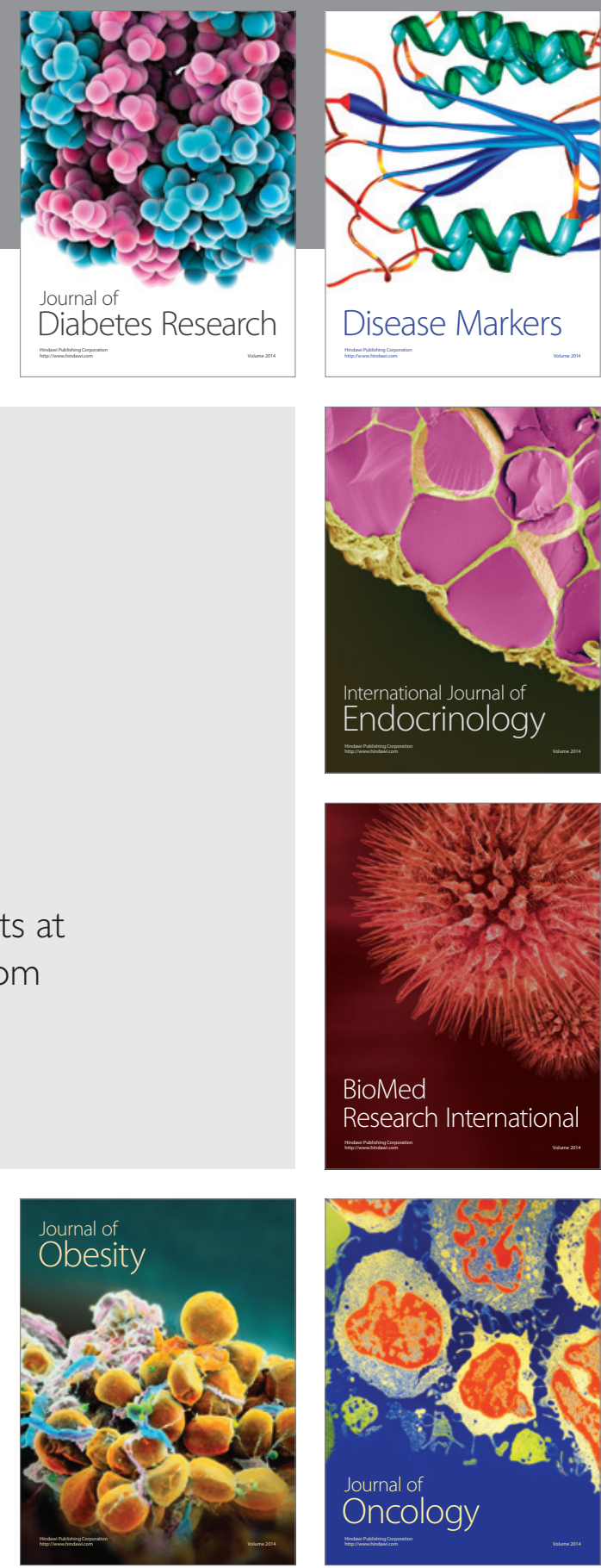

Disease Markers
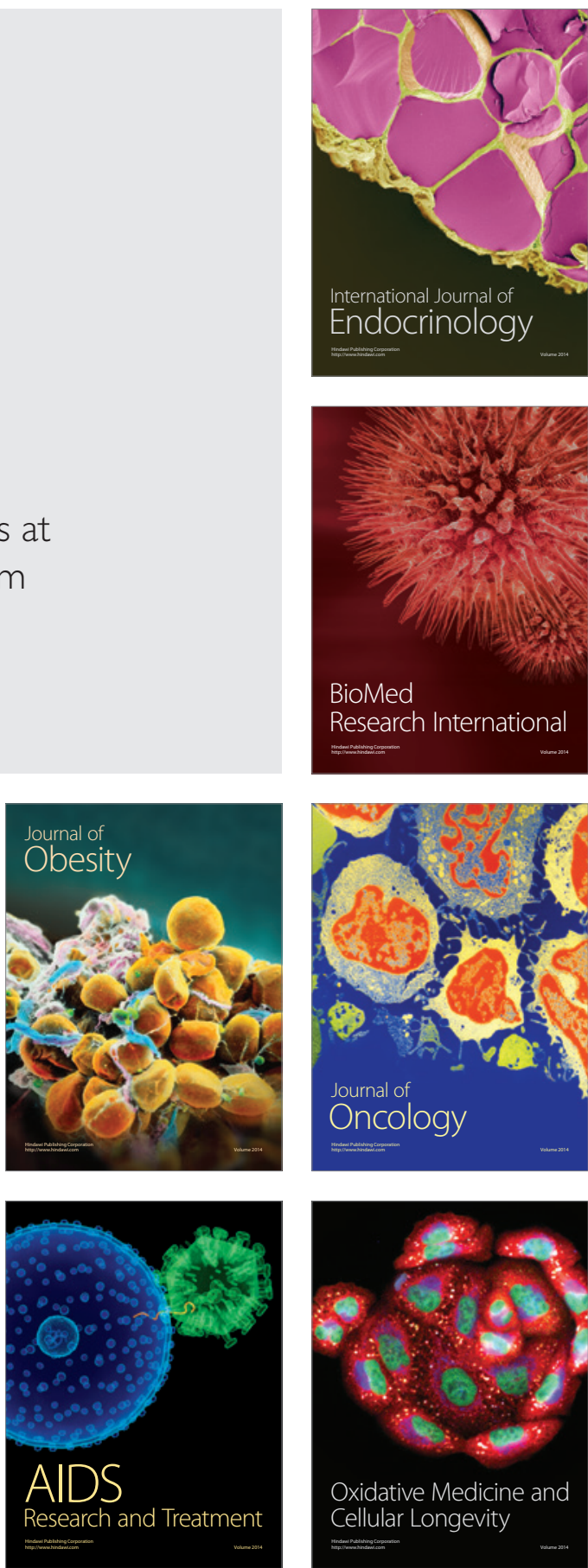